\title{
РАЗРАБОТКА СОВРЕМЕННОЙ МОДЕЛИ ПРЕДУНИВЕРСИТАРИЯ В УСЛОВИЯХ ОБРАЗОВАТЕЛЬНОГО ПРОЦЕССА ТЕХНИЧЕСКОГО ВУЗА
}

\author{
Е. Е. Сартакова, В. В. Макеев
}

Томский государственный педагогический университет, Томск

Анализируется процесс разработки модели предуниверситария в условиях технического вуза как комплексный механизм организации профориентационной и образовательной деятельности с абитуриентами. Подчеркивается, что предуниверситарий обеспечивает вузу поиск, отбор, сопровождение, профессиональную ориентацию и довузовскую подготовку абитуриентов к прохождению вступительных испытаний и обучению, создает условия для погружения обучающихся в образовательную и культурную среду университета. Разрабатываемая модель носит комплексный характер, так как развивается на основе инвариантных составляющих аналогичных организаций, учитывает опыт деятельности предуниверситариев, реализующих образовательную деятельность в различных вузах на территории России. Отличительными характеристиками модели предуниверситария являются целостность, открытость, вариативность, совокупность взаимосвязанных структурных компонентов (концептуально-целевого, содержательного, ресурсного, технологического и результативно-оценочного). Научная новизна исследования заключается в проработке модели предуниверситария технического университета, деятельность которого направлена на организацию сетевых моделей профильного обучения старшеклассников при сохранении традиционных форм довузовской подготовки; реализацию процесса психологической, интеллектуальной, культурной подготовки будущего студента к обучению в вузе через различные формы участия в системной образовательной и воспитательной работе предуниверситариев; обеспечение предпрофильной подготовки обучающихся (в том числе и ранней) и др. Теоретическая значимость работы связана с выявлением и описанием ключевых элементов деятельности предуниверситария безотносительно специфики отдельных университетов и моделей.

Ключевые слова: предуниверситарий, профессиональная ориентация, довузовская подготовка, проиесс набора в университет, работа с абитуриентами, модель предуниверситария.

В настоящее время в каждом университете существуют собственные системы довузовской подготовки и профориентации обучающихся, в том числе модели предуниверситариев, о которых мы говорили раньше. Однако необходимо отметить, что все представленные ранее модели имеют специфические особенности и характеристики, не всегда тиражируемые в условиях различных вузов, в особенности технических. С целью создания наиболее универсальной модели мы провели настоящее исследование.

Для нас предуниверситарии могут быть организованы и как самостоятельное образовательное структурное подразделение университета, реализующее образовательные программы разного уровня, и как самостоятельная образовательная организация, действующая в рамках сетевого взаимодействия с вузом; а также как подразделение университета, обеспечивающее реализацию только дополнительных образовательных программ, также осуществляющее блок профориентационной работы. Для разработки и реализации нашей модели мы выбрали третий путь. 
В процессе разработки модели предуниверситария в условиях реализации образовательного процесса технического вуза нами были использованы материалы работ А. Н. Дахина [1], А. Г. Бурды и Г. П. Бурды [2] для определения понятия «модель» и изучения особенностей его управленческой разновидности.

Представленная модель включает следующие компоненты: мотивационно-целевой, содержательный, технологический, оценочно-результативный.

Мотивационно-целевой компонент модели. Содержание мотивационно-целевого компонента модели обусловлено требованиями к абитуриенту со стороны современного технического университета:

1. Готовность к успешному освоению образовательных программ предметных областей, необходимых для обучения в техническом вузе (в первую очередь профильной математики, физики, информатики), и как результат - успешное прохождение итоговой аттестации в форме Единого государственного экзамена (ЕГЭ) для достижения необходимых показателей среднего балла.

2. Устойчивая мотивация для поступления на инженерно-технические специальности.

3. Погруженность в образовательную среду и культурное пространство университета на этапе обучения в школе с целью своевременного выбора вуза для последующего поступления.

4. Сформированные базовые надпредметные компетенции и личностные качества для вовлечения во внеучебную деятельность университета после поступления в целях формирования профессиональной компетентности и конкурентноспособности специалиста на рынке труда.

Цель проектирования и реализации модели предуниверситария в условиях образовательного процесса в техническом вузе - создание системы профориентационной работы и довузовской подготовки абитуриентов, которая позволит обучающимся общеобразовательных и профессиональных образовательных организаций успешно подготовиться к поступлению в университет в процессе обучения по дополнительным образовательным программам, а также обеспечит поиск, отбор и сопровождение высокомотивированных и наиболее подготовленных к обучению в данном вузе обучающихся. Сформулированная нами цель находит аналитическое подкрепление в работах современных исследователей данных моделей [3-5] и сетевого взаимодействия [6].

Методологической основой модели являются системно-деятельностный, функциональный и национально-региональный подходы, управление развитием по результатам. На основании работы Т. А. Жданко [7] охарактеризуем особенности системно-деятельностного подхода: 1) нацеленность на развитие личности; 2) формирование гражданской идентичности; 3) обеспечение возможности формирования ценностных ориентиров; 4) учет индивидуальных особенностей развития личности обучающегося при разработке образовательных программ; 5) отбор присущих индивидуальным особенностям развития личности обучающегося форм деятельности.

В процессе реализации системно-деятельностного подхода в рамках нашей модели мы можем отметить, что результативность профориентационной работы требует осуществления системной деятельности в продолжительный период; погружения обучающихся в научно-образовательную среду университета; привлечения партнеров и использования ресурсов других организаций.

Исходя из основных положений системно-деятельностного подхода, мы выделяем принципы и методологические подходы проектирования и реализации нашей модели: национально-региональный подход, управление развитием по результатам, функциональный подход. 
Содержательный и технологический компоненты модели предполагают процесс формирования содержательного наполнения самой системы профориентационной работы и довузовской подготовки в университете, а также профильного подразделения - предуниверситария.

Первый этап данной работы связан с определением нормативно-правовых основ модели. Базовыми документами являются Федеральный закон «Об образовании в Российской Федерации» от 29.12.2012 г. № 273-Ф3, федеральные государственные образовательные стандарты основного общего и среднего общего образования, локальные акты университета.

В процессе реализации деятельности по профессиональной ориентации обучающихся и их довузовской подготовке используется следующий комплекс документов: устав университета, выступающий основным локальных правоустанавливающим актом образовательной организации; комплексная программа развития университета на 2018-2022 гг., определяющая указанные направления деятельности как приоритетные; положение о предуниверситарии, положения о его структурных подразделениях для определения блока компетенции моделируемой структуры; положения по направлениям образовательных программ; образовательные программы, проекты, описывающие содержание образования; договоры о сотрудничестве, определяющие полномочия, статус и систему взаимоотношений между вузом и школами-партнерами; договоры, в том числе трудовые, определяющие правила взаимодействия субъектов; локальные акты, регулирующие процесс управления системой; должностные инструкции работников и преподавательского состава.

Второй этап обусловлен определением самой модели подразделения и управления системой. В условиях технического вуза наиболее оптимальной является организационная модель, основанная на координации всех подразделений университета, осуществляющих профориентационную работу (предуниверситарий, приемная комиссия, выпускающие кафедры, факультеты и институты, управление информационной политики), включая также внешние организации, заинтересованные в развитии данного направления (школы-партнеры, муниципальные и региональные координаторы и операторы профориентационной работы, партнерские организации).

Предуниверситарий также осуществляет инвентаризацию и сосредоточение ресурсов университета для проведения профессиональной ориентации и реализации дополнительных образовательных программ довузовской подготовки. Ведущим принципом взаимодействия выступает саморегуляция: каждый участник на каждом этапе поддерживает отношения с определенным количеством субъектов системы, при этом сама структура данных связей имеет гибкий характер и подлежит развитию в случае необходимости.

Основой функционирования, в случае профориентационной деятельности, могут быть конкретные профильные программы и проекты, носящие временный или постоянный характер (олимпиада, конференция, конкурс, образовательное событие, мастер-класс); в рамках довузовской подготовки - реализация образовательных программ. Каждый новый проект может приводить к созданию временной иерархической структуры для достижения определенных целей на данном конкретном уровне, опираясь на исследовательские работы ученых [6].

Такая система взаимодействия может быть построена как на стратегии «Синтез», так и на стратегии кластерных сетей [6]. Стратегия «Синтез» в нашем случае предполагает объединение учебных и административных подразделений университета, партнерских организаций, образовательных организаций-партнеров. Такое взаимодействие позволяет создать целостную и комплексную систему профессиональной ориентации обучающихся и сделать процесс реализации образовательных программ более интегрированным и наполненным, а 
также выстроить систему непрерывного образования от школы/техникума к вузу через вертикальные связи по уровням образования и горизонтальные - через партнерство.

Стратегия развития кластерных сетей объединяет группы учебных и административных подразделений, образовательных организаций и взаимодействующих с ними партнеров, которые осуществляют определенную деятельность по какому-либо направлению в той или иной области (архитектурное довузовское образование, профориентация в области информационных технологий в строительстве), что позволяет взаимодополнять данную работу и объединять ресурсы для достижения общих задач. Создание такого кластера вызвано объективной потребностью консолидации на одной содержательной базе вокруг университета при возможной реализации проектов на разных площадках в определенной образовательной области. В такое кластерное взаимодействие могут включаться как профильные учебные кафедры вместе с предуниверситарием и школами-партнерами, в перспективе - предприятия, потенциальные работодатели, различные организации, реализующие образовательные программы и проекты.

При создании таких образовательных кластеров выстраиваются горизонтальные связи для реализации долгосрочных проектов и программ, обеспечивается взаимодополняемость различными видами ресурсов, что позволяет создать больше возможностей для удовлетворения запросов обучающихся.

На этапе создания такого «кластера» как организационной основы для нормативноправового обеспечения достаточной является система договорных отношений. В условиях деятельности предунивреситария в данном формате выступает система договоров о сотрудничестве; также необходимо отметить, что разработка такой модели возможна в рамках образовательной организации высшего образования, которая реализует различные формы и уровни образования, в том числе не только образовательные программы высшего образования, но и дополнительные образовательные программы для детей и взрослых, а также образовательные программы профессионального образования.

Методологически вышеописанный феномен связан с педагогикой многообразия; исследовательские материалы [8] в данной работе мы будем использовать при построении методологической конструкции. Многообразие образования - это разнообразие образовательных программ, образовательных организаций, их реализующих, форм и уровней образования. В данной работе принцип многообразия связан с образовательной вариативностью программ и проектов, многообразием направлений профориентационной работы и реализацией дополнительных образовательных программ.

Институциональное многообразие связано с различными моделями предуниверситариев, при этом многообразие как ведущий принцип организационного устройства такой модели предполагает его внутреннее строение, целеполагание, методологию и организацию функционирования.

В социально-педагогическом контексте деятельности предуниверситария принцип многообразия дает возможность сформировать такую образовательную систему, которая способна адекватно отвечать запросам стремительных социально-экономических изменений, множественности и разнообразию запросов общества и государства, образовательным потребностям обучающихся, а также может своевременно адаптироваться к ним.

Многообразие также находится в основе организации образовательного процесса и образовательной среды предуниверситария, что ведет к существенному изменению образовательной системы: появляются такие ее характеристики, как гибкость, мобильность, динамичность, способность к самоизменениям и саморазвитию, созданию широкого выбора образовательных услуг. Указанные характеристики напрямую связаны с диагностикой, 
процессами проектирования и реализации дополнительных образовательных программ, контроля и коррекции.

Исходя из вышесказанного, мы можем определить основной признак такой модели планирование и реализация дополнительных образовательных программ, профориентационных проектов и программ, которые могут быть реализованы через систему партнерских взаимоотношений, с использованием материально-технической базы и кадрового обеспечения университета совместно с организациями-партнерами на основе соглашений о сотрудничестве. В настоящее время потенциал взаимодействия вузов и общеобразовательных учреждений подкрепляется как действующим законодательством [9], так и опытом работы университетов [10].

В ходе данной работы нами было установлено, что модели предуниверситариев могут различаться, однако существует ряд присущих всем моделям общих аспектов:

1. Нацеленность данных моделей на построение системы профильного обучения старшеклассника с переносом центра тяжести реализации образовательных программ на образовательные организации высшего образования в части обеспечения кадровым составом преподавателей, материально-технических и лабораторно-исследовательских условий, а также формирования университетской культуры у будущих абитуриентов.

2. Комплексный характер образовательной деятельности заключается в сокращении естественного разрыва временных, физических, финансовых ресурсов обучающихся и их семей путем концентрации образовательного процесса или на базе университета, или его структурных подразделений / профильных классов, в том числе общеобразовательных учреждений, что позволяет ребенку получать исчерпывающий объем образовательных услуг как школы, так и университета на одной площадке.

3. Участие органов государственной власти и местного самоуправления в поддержке реализации данных проектов и интеграция их в процессы решения задач регионального социально-экономического и культурного развития.

4. Достаточно серьезный фокус внимания на углубленную подготовку для прохождения обучающимися/слушателями предуниверситариев и других подразделений ЕГЭ по причине достаточно высокого уровня среднего балла при поступлении в вуз.

5. Организация процесса психологической, интеллектуальной, культурной подготовки абитуриента к обучению в вузе посредством участия в системной воспитательной работе предуниверситариев и других моделей.

6. Обеспечение ранней профориентации и профилизации обучающихся с целью помощи в определении выбора обучающимся дальнейшей образовательной траектории до перехода в выпускной класс, что дает возможность ребенку при необходимости перейти в другое образовательное учреждение.

7. Формирование инновационных моделей и форм привлечения абитуриентов в университет, таких как профильные классы, сетевые образовательные программы с общеобразовательными учреждениями и профориентационные проекты.

8. Традиционное осуществление классической довузовской подготовки к вступительным испытаниям и различная модификация такой работы в зависимости от задач и специфики процесса набора в университет.

9. Реорганизация вузами систем профориентационной и довузовской работы с абитуриентами с широким вовлечением различных блоков управления образовательной организацией (научный, воспитательный, учебный, административно-хозяйственный) и интеграции в данные процессы значительного числа серьезных специалистов из числа профессорскопреподавательского состава университетов. 
Такая модель позволяет выделить специфику предуниверситария, в первую очередь институциональную. В отличие от других форм подготовки абитуриента к поступлению и профориентационной работы с ним, предуниверситарии - комплексная система довузовской подготовки и профориентационной работы университета, реализуемая на базе вуза через дополнительные образовательные программы, как предметного, так и специализированного профильного характера, с широким привлечением его кадрового состава, материально-технической базы и образовательной среды. Цель деятельности предуниверситария в данном случае - создание условий для обучающихся независимо от образовательной организации и наличия соответствующего профиля в школе, а также получение комплекса образовательных услуг и возможности сделать осознанный выбор направления обучения.

К задачам деятельности предуниверситария относятся: 1) обеспечение доступного, качественного образования через проектирование и реализацию комплекса дополнительных образовательных программ, в том числе с использованием дистанционных и электронных образовательных технологий; 2) организация внеучебной деятельности, включая вовлечение слушателей в образовательную культуру университета, участие в различных мероприятиях, формирование социальной компетентности; 3) кадровое обеспечение реализации образовательных программ, специфика формирования которого обусловлена профессорско-преподавательским составом университета, действующими на его базе научными школами и творческими академическими коллективами; 4) создание материально-технической базы, информационной образовательной среды, учебно-методического комплекса для реализации дополнительных образовательных программ; 5) построение системы управления профориентационной работой и довузовской подготовкой университета; 6) разработка нормативно-правового обеспечения данной деятельности.

В состав технологического компонента нашей модели мы можем включить последовательность этапов проектирования и реализации дополнительных образовательных программ, а также профориентационных проектов и программ. Данный компонент модели организации процесса управления предполагает содержание деятельности по осуществлению моделируемого процесса. С этой целью деятельность в модели структурирована по этапам, направлениям работы, реализуемым в деятельности принципам, условиям эффективности моделируемого процесса и т. д. Этапы реализации модели организации образовательного процесса связаны с проектированием, планированием, ресурсным обеспечением, координацией и контролем (табл. 1).

Таблица 1

Этапь реализацчии модели организащии образовательного процесса

\begin{tabular}{|c|c|c|}
\hline Этап & Задачи & Результаты \\
\hline $\begin{array}{l}\text { Проектирование } \\
\text { и планирование }\end{array}$ & $\begin{array}{l}\text { Проектирование модели, } \\
\text { содержание дополнительных } \\
\text { образовательных программ, } \\
\text { содержание профориентацион- } \\
\text { ных проектов и программ, } \\
\text { способов их реализации }\end{array}$ & $\begin{array}{l}\text { 1. Пакет дополнительных образовательных } \\
\text { программ. } \\
\text { 2. Комплексные учебные планы. } \\
\text { 3. Пакет профориентационных проектов } \\
\text { и программ. } \\
\text { 4. Нормативно-правовая база }\end{array}$ \\
\hline $\begin{array}{l}\text { Ресурсное } \\
\text { обеспечение }\end{array}$ & $\begin{array}{l}\text { Проектирование и формирова- } \\
\text { ние кадрового ресурса, матери- } \\
\text { ально-технической и учебно- } \\
\text { методической базы для } \\
\text { реализации образовательных } \\
\text { программ }\end{array}$ & $\begin{array}{l}\text { 1. Реализация кадрового обеспечения. } \\
\text { 2. Реализация ресурсного обеспечения }\end{array}$ \\
\hline
\end{tabular}


Сартакова Е. Е., Макеев В. В. Разработка современной модели педуниверситария...

\begin{tabular}{|c|l|l|}
\hline \multicolumn{1}{|c|}{ Этап } & \multicolumn{1}{|c|}{ Задачи } & \multicolumn{1}{|c|}{ Результаты } \\
\hline Координация & $\begin{array}{l}\text { Оперативная деятельность по } \\
\text { организации процесса реализа- } \\
\text { ции дополнительных образова- } \\
\text { тельных программ, а также } \\
\text { профориентационных проектов } \\
\text { и программ }\end{array}$ & $\begin{array}{l}\text { Организация процесса реализации дополнительных } \\
\text { образовательных программ, а также профориента- } \\
\text { ционных проектов и программ }\end{array}$ \\
\hline Контроль & $\begin{array}{l}\text { Сравнительный анализ качества реализации дополни- } \\
\text { Мониторинг качества организа- } \\
\text { ции образовательного процесса образовательных программ, а также профори- } \\
\text { ентационных проектов и программ, включая: } \\
\text { 1. Результаты диагностики уровня удовлетворенно- } \\
\text { сти образовательными услугами. } \\
\text { 2. Результаты диагностики образовательных } \\
\text { потребностей в дополнительных образовательных } \\
\text { программах, профориентационных проектах и } \\
\text { программах. } \\
\text { 3. Результаты мониторинга качества образования. } \\
\text { 4. Качество кадрового ресурса }\end{array}$ \\
\hline
\end{tabular}

Представленные выше этапы реализации позволяют нам обеспечить системную работу по сопровождению апробации модели предуниверситария, в том числе на базе различных университетов. Мониторинг качества реализации модели предуниверситария реализуется через систему критериев анализа результативности данной модели в условиях технического вуза (табл. 2).

Таблица 2

\section{Критерии анализа результативности реализации модели}

предуниверситария технического вуза

\begin{tabular}{|c|c|}
\hline Мероприятие & Индикаторы мероприятия \\
\hline \multirow{5}{*}{$\begin{array}{l}\text { БЛОК 1. Подготовка широко- } \\
\text { го спектра дополнительных } \\
\text { образовательных программ } \\
\text { для детей разного возраста, } \\
\text { система привлечения ППС } \\
\text { вуза и других вузов }\end{array}$} & Создание профильных инженерно-технических классов (групп) \\
\hline & $\begin{array}{l}\text { Участие ППС вуза в разработке программ, внедрение новых методов: } \\
\text { количество программ; число ППС вуза, вовлеченных в разработку программ }\end{array}$ \\
\hline & $\begin{array}{l}\text { Создание системы привлечения работодателей и практикующих специали- } \\
\text { стов к реализации программ: число привлеченных работодателей и практи- } \\
\text { кующих специалистов }\end{array}$ \\
\hline & $\begin{array}{l}\text { Создание системы мотивации ППС вуза и других вузов для работы в предуни- } \\
\text { верситарии: доля слушателей предуниверситария, участвующих в проектных } \\
\text { конкурсах, олимпиадах и конференциях в результате работы педагогов вуза. } \\
\text { Доля слушателей предуниверситария, побеждающих в проектных конкурсах, } \\
\text { олимпиадах и конференциях в результате работы педагогов вуза }\end{array}$ \\
\hline & Количество кураторов/тьюторов \\
\hline \multirow{3}{*}{$\begin{array}{l}\text { БЛОК 2. Разработка метода } \\
\text { оценки способностей и } \\
\text { мотивации детей }\end{array}$} & Разработка системы профориентационного тестирования \\
\hline & $\begin{array}{l}\text { Разработка ряда мероприятий для формирования сообщества: } \\
\text { количество мероприятий в год для формирования сообщества и повышения } \\
\text { мотивации. Доля детей, участвующих во всех проектах предуниверситария, } \\
\text { от числа всех обучающихя предуниверситария }\end{array}$ \\
\hline & $\begin{array}{l}\text { Создание образовательно-игрового портала для отслеживания личностного } \\
\text { роста ребенка }\end{array}$ \\
\hline \multirow{3}{*}{$\begin{array}{l}\text { БЛОК 3. Обеспечение ежегод- } \\
\text { ного набора школьников в } \\
\text { предуниверситарий и вуз }\end{array}$} & $\begin{array}{l}\text { Формирование контингента предуниверситария: количество обучающихся в } \\
\text { Предуниверситарии, доля выпускников предуниверситария, поступивших в } \\
\text { вуз (от общего числа выпускников предуниверситария), средний балл ЕГЭ } \\
\text { выпускника предуниверситария, число слушателей предуниверситария, } \\
\text { получающих образовательные услуги дистанционно }\end{array}$ \\
\hline & $\begin{array}{l}\text { Формирование контингента вуза: доля поступивших в вуз томичей (от } \\
\text { общего числа поступивших в вуз) }\end{array}$ \\
\hline & $\begin{array}{l}\text { Количество мероприятий в год для продвижения и набора (фестивали наук, } \\
\text { профпробы, мастер-классы и родительские собрания) }\end{array}$ \\
\hline
\end{tabular}

Примечание. ППС - профрессорско-преподавательский состав; ЕГЭ - единый государственный экзамен. 
На основании технологии построения аналитических матриц [11] можно охарактеризовать критерии данного мониторинга.

Критериями мониторинга станут показатели среднего балла ЕГЭ выпускников предуниверситария как одна из базовых метрик повышения качества набора в университет; доля обучающихся в предуниверситарии, поступивших в вуз, как показатель результативности профориентации слушателей предуниверситария; доля обучающихся в предуниверситарии, участвующих в конкурсах и конференциях от имени вуза, как условие создания научно-исследовательской, творческой и соревновательной среды в вузе для слушателей дополнительных образовательных программ; доля слушателей, в том числе из числа иностранных граждан, получающих образование дистанционно, от общего количества обучающихся в предуниверситарии, выступает критерием доступности образовательных услуг; доля профессорско-преподавательского состава вуза, вовлеченного в работу со слушателями предуниверситария, как важный интегративный показатель привлечения высококвалифицированных преподавательских кадров к данной работе.

На основе разработанной нами модели и проведенного исследования мы можем выстроить структурную модель предуниверситария как подразделения в составе университета (рисунок).

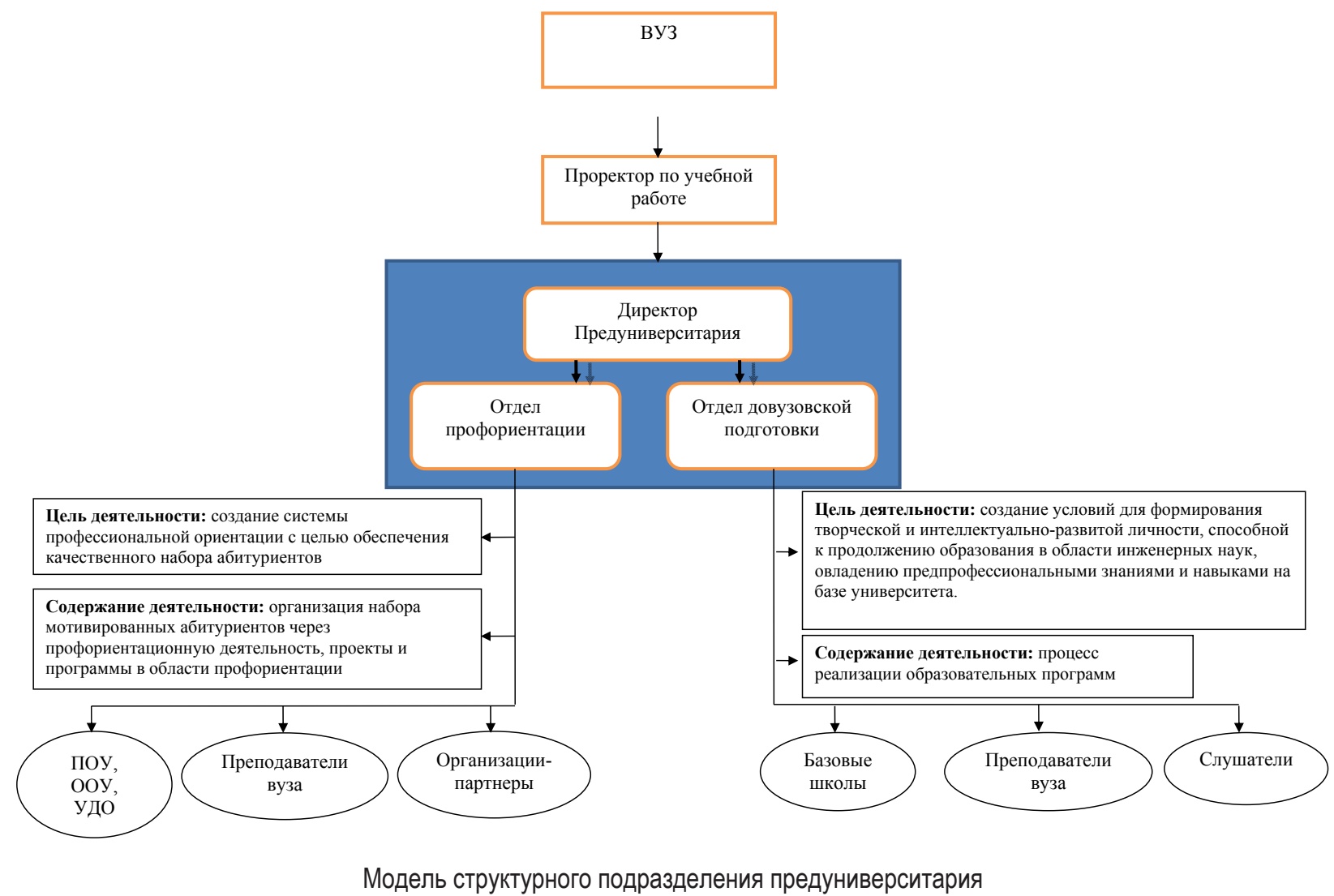

Данное структурное подразделение, на наш взгляд, должно находиться в ведении проректора по учебной работе университета, что связано, во-первых, с самостоятельностью подразделения в реализации образовательного процесса в рамках дополнительных образовательных программ; во-вторых, в обеспечении выполнения задач набора абитуриентов, что становится одним из базовых требований для организации образовательной деятельности учебного блока университета. Данное подразделение возглавляется руководителем (директором), в его состав входят два отдела, реализующие профильные направления: 
1) отдел довузовской подготовки, обеспечивающий процесс реализации дополнительных образовательных программ, целью которого является создание условий для формирования творческой и интеллектуально-развитой личности, способной к продолжению образования в области инженерных наук, овладению предпрофессиональными знаниями и навыками на базе университета. Субъектами данной деятельности выступают: базовые школы; преподавательский состав университета, привлеченный для реализации образовательных программ; слушатели предуниверситария из числа обучающихся общеобразовательных и профессиональных образовательных организаций;

2) отдел профориентации, обеспечивающий координацию деятельности подразделений университета в области профессиональной ориентации обучающихся общеобразовательных и профессиональных образовательных организаций с целью качественного набора мотивированных абитуриентов через профориентационную деятельность, проекты и программы в области профориентации. Субъектами данной деятельности выступают: общеобразовательные, профессиональные образовательные организации, учреждения дополнительного образования, вовлеченные в профориентационную деятельность; преподавательский состав университета, привлеченный для реализации профориентационных проектов и программ; организации-партнеры, заинтересованные в профессиональной ориентации обучающихся, в том числе на профильные направления.

В заключение мы хотим отметить, что разработанная нами и представленная в настоящей статье модель предуниверситария включает: 1) структуру предуниверситария как подразделения в составе вуза; 2) содержательную управленческую деятельность по разработке и реализации дополнительных образовательных программ, профориентационных проектов и программ: целеполагание, направленное на организацию системы подготовки абитуриентов к поступлению в университет; содержание образования, представленное пакетом дополнительных образовательных программ, профориентационных проектов и программ; технологии реализации, которые обеспечивают систему управленческих действий по их реализации, регулированию и контролю; условия, влияющие на реализацию модели: организация комплексной системы реализации дополнительных образовательных программ, профориентационных проектов и программ; разработка и апробация мониторинга результативности модели предуниверситария.

Данная модель может быть использована при проектировании и создании профильных моделей на базе других технических вузов, отражает необходимый базовый минимум для организации качественной профориентационной и довузовской подготовки в условиях образовательного процесса в техническом вузе.

\section{Список литературы}

1. Дахин А. Н. Моделирование в педагогике. URL: https://cyberleninka.ru/article/v/modelirovanie-v-pedagogike (дата обращения: 16.12.2019).

2. Бурда А. Г., Бурда Г. П. Моделирование в управлении: учеб. пособие (курс лекций). Краснодар, 2015. 250 с.

3. Фиофанова О. А., Елютин С., Пастухов А. Предуниверситарий: новая модель профильного образования // Сборник конференции: Тенденции развития образования: что такое эффективная школа и эффективный детский сад? М., 2014. С. 178-191.

4. Аверьянова М. Н., Кирт Н. Л. Анализ российского опыта создания инновационных образовательных структур в вузах // Непрерывное образование: XXI век. 2017. № 4 (20). С. 106-113.

5. Кокин С. М., Никитенко В., Пауткина А., Прунцев А. Предуниверситарий - важный элемент современного школьного образования // Необратимые процессы в природе и технике: сб. конф. М.: МГТУ, 2017. С. 165-168.

6. Медведев И. Б. Сетевая организация образовательного процесса в современной сельской школе: дис. ... канд. пед. наук. Великий Новгород, 2018. 235 с. 
7. Жданко Т. А. Системно-деятельностный подход: сущностная характеристика и принципы реализации. URL: https://cyberleninka.ru/article/n/sistemno-deyatelnostnyy-podhod-suschnostnaya-harakteristika-i-printsipyrealizatsii (дата обращения: 16.12.2019).

8. Менеджмент многообразия в гетерогенных организациях: учеб. пособие / М. Н. Певзнер, П. А. Петряков, В. В. Стадник, У. Альгермиссен. Хмельницкий: ФОП А. С. Гонта, 2016. 354 с.

9. Федеральный закон от 29.12.2012 г. № 273-Ф3 «Об образовании в Российской Федерации». URL: http:// www.consultant.ru/document/cons_doc_LAW_140174/499cc91fbe852d6839d4de3b173bb4953a33419c/ (дата обращения: 16.12.2019).

10. Прозументова Г. Н. Потенциал взаимодействия вузов и школ: эмпирические модели // Вестник Томского государственного университета. 2012. № 358. С. 182-187.

11. Елисеева А. А. Реализация образовательного потенциала сетевого взаимодействия «школа-вуз» на региональном уровне: дис. ... канд. пед. наук. Томск, 2019. 262 с.

Сартакова Елена Евгеньевна, доктор педагогических наук, профессор, Томский государственный педагогический университет (ул. Киевская, 60, г. Томск, Россия, 634061).

E-mail: lopolit@rambler.ru

Макеев Владимир Викторович, магистрант, Томский государственный педагогический университет (ул. Киевская, 60, г. Томск, Россия, 634061). E-mail: VLVmakeev88@gmail.com

Материал поступил в редакцию 13.01.2020.

DOI 10.23951/2307-6127-2020-2-179-189

\section{DEVELOPMENT OF THE MODERN MODEL OF PRE-UNIVERSITY IN THE CONDITIONS OF THE EDUCATIONAL PROCESS OF A TECHNICAL UNIVERSITY}

\section{V. Makeyev, E. E. Sartakova}

\section{Tomsk State Pedagogical University, Tomsk, Russian Federation}

The article is devoted to the process of developing a model of a pre-university in a technical university, which meets the modern requirements of a modern technical university, and provides the possibility of replication in various educational institutions of higher education of a technical profile, without reference to certain characteristics and creates the conditions for the implementation of the university's specifics in the educational process. The article is devoted to the process of developing a pre-university model in the educational process of a modern educational institution of higher education of a technical profile, in which the pre-university is a mechanism for searching, selecting, supporting, vocational guidance and pre-university preparation of applicants for entrance examinations and training at a technical university, creates conditions for immersing students in educational and cultural environment of the university, which allows to determine to choose a profession and a university in advance, and, if necessary, to change the profile of training. The developed model takes into account the experience of various analogues of pre-university students implementing educational activities in various universities in Russia. The scientific novelty of the study is to work out all the elements of the pre-university model being created, which can be created on the basis of any technical university regardless of its starting conditions and limitations, and also provide opportunities for taking into account the specifics of the university, including: a) the creation of a system of pre-university training at the university, taking into account priority tasks in the field of recruitment and the possibility of creating conditions for ensuring the selection of various educational paths; b) the organization of 
coordination of career guidance at the university. The theoretical significance of the work is associated with the identification and description of the key elements of the pre-university activity regardless of the specifics of individual universities and models.

Keywords: pre-university, vocational guidance, pre-university preparation, university enrollment process, work with applicants, pre-university model.

\section{References}

1. Dakhin A. N. Modelirovaniye v pedagogike [Modeling in pedagogy] (in Russian). URL: https://cyberleninka.ru/ article/v/modelirovanie-v-pedagogike (accessed 16 December 2019).

2. Burda A. G., Burda G. P. Modelirovaniye v upravlenii: uchebnoye posobiye (kurs lektsiy) [Modeling in management: a training manual (lecture course)]. Krasnodar, Kuban SAU Publ., 2015. 250 p. (in Russian).

3. Fiofanova O. A., Elyutin S. O., Pastukhov A. B. Preduniversitariy: novaya model' profil'nogo obrazovaniya [Preuniversity: a new model of specialized education]. Sbornik konferentsii: Tendentsii razvitiya obrazovaniya: chto takoye effektivnaya shkola i effektivnyy detskiy sad? [Conference proceedings: Trends in the development of education: what is an effective school and an effective kindergarten?]. Moscow, 2014. Pp. 178-191 (in Russian).

4. Aver'yanova M. N., Kirt N. L. Analiz rossiyskogo opyta sozdaniya innovatsionnykh obrazovatel'nykh struktur v vuzakh [Analysis of Russian experience in creating innovative educational structures in universities]. Nepreryvnoye obrazovaniye: XXI vek-Lifelong Education: the XXI Century, 2017, no. 4 (20), pp. 106-113 (in Russian).

5. Kokin S. M., Nikitenko V. A., Pautkina A. V., Pruntsev A. P. Preduniversitariy - vazhnyy element sovremennogo shkol'nogo obrazovaniya [Pre-university - an important element of modern school education]. Neobratimye protsessy v prirode i tekhnike: sbornik konferentsii [Irreversible processes in nature and technology: conference proceedings] Moscow, MGTU, 2017. Pp. 165-168 (in Russian).

6. Medvedev I. B. Setevaya organizatsiya obrazovatel'nogo protsessa v sovremennoy sel'skoy shkole. Dis. kand. ped. nauk [Network organization of the educational process in a modern rural school. Diss. cand. of ped. sci.]. Velikiy Novgorod, 2018. 284 p. (in Russian).

7. Zhdanko T. A. Sistemno-deyatel'nostnyy podkhod: sushchnostnaya kharakteristika i printsipy realizatsii [Systemactivity approach: the essential characteristic and principles of implementation] (in Russian). URL: https://cyberleninka.ru/article/n/sistemno-deyatelnostnyy-podhod-suschnostnaya-harakteristika-i-printsipy-realizatsii (accessed 16 December 2019).

8. Pevzner M. N., Petryakov P. A., Stadnik V. V., Al'germissen U. Menedzhment mnogoobraziya v geterogennykh organizatsiyakh: uchebnoye posobiye [Diversity management in heterogeneous organizations: tutorial]. Khmel'nitsky, FOPA.S. Gonta Publ., 2016. 354 p. (in Russian).

9. Federal'nyy zakon "Ob obrazovanii v Rossiyskoy Federatsii" ot 29.12.2012 № 273-FZ [Federal Law "On Education in the Russian Federation" dated December 29, 2012 No. 273-FZ] (in Russian). URL: http://www.consultant. ru/document/cons_doc_LAW_140174/(accessed 16 December 2019).

10. Prozumentova G. N. Potentsial vzaimodeystviya vuzov i shkol: empiricheskiye modeli [The potential for interaction between universities and schools: empirical models]. Vestnik Tomskogo Gosudarstvennogo Universiteta Tomsk State University Journal, 2012, no. 358, pp. 182-187 (in Russian).

11. Eliseyeva A. A. Realizatsiya obrazovatel'nogo potentsiala setevogo vzaimodeystviya "shkola-vuz" na regional'nom urovne. Dis. kand. ped. nauk [Realization of the educational potential of the school-university network interaction at the regional level. Diss. of cand. of ped. sci.]. Tomsk, 2019. 262 p. (in Russian).

Sartakova E. E., Tomsk State Pedagogical University (ul. Kiyevskaya, 60, Tomsk, Russian Federation, 634061). E-mail: lopolit@rambler.ru

Makeyev V. V., Tomsk State Pedagogical University (ul. Kiyevskaya, 60, Tomsk, Russian Federation, 634061). E-mail: VLVmakeev88@gmail.com 